\title{
Cooperative Learning Strategies and their Impact on the Promotion of Editorial Expression Students of the Department of Arabic Language Teaching at the Islamic University of Tulung Agung
}

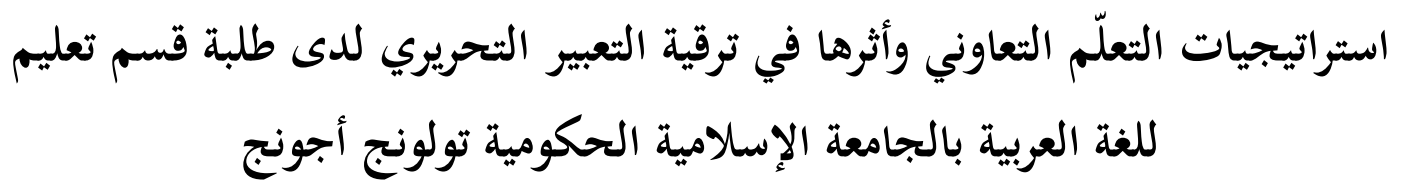

Luthfi Abdul Manaf

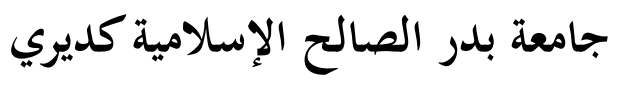

luthfiabdulmanaf@gmail.com

\section{Summary of the Research}

The aim of this research is to identify cooperative learning strategies in enhancing the skill of written expression and understanding the impact of these strategies. The introduction of collaborative learning in the promotion of the skill of written expression among students at the Department of Arabic Language Education at the Islamic University of Tolong Agung. Use this search descriptive qualitative portal. The researcher also used research tools to collect data, namely observation, interview and documents. Data analysis is data reduction, data presentation, and data validation by constant comparison. To examine the validity of the data, the researcher is working to prolong the times of attendance and tripartite and discuss with some of the brothers.

The results of this research showed that the goals of teaching expression in the cooperative learning strategy are using steps such as the teacher to set goals, materials and teaching methods and then set the procedures of education by dividing the students into six groups. The teacher prepares the working drawings for the students with different colors for each group, distributed to each group. A student from the groups began working by walking around the teacher to observe the positive tingling atmosphere. After the students finished working, each group discussed their work in front of another group, and then the teacher evaluated the students' work. The use of cooperative learning strategies has a significant impact on students' skill upgrading in the expression of discretion.

Keywords: strategies, collaborative learning, editorial expression. 


\section{مستخلص البحث}

يهاف هذا البحث إلى معرفة إستراتيجات التعلم التعاوي في ترقية مهارة التعبير

التحريري ومعرفة أثر تلك الاستراتيجات مدخل التعلم التعاوني في ترقية مهارة التعبير التحريري لدى طلبة لدى قسم التربية للغة العربية بالجامعة الإسلامية الحكومية تولونج

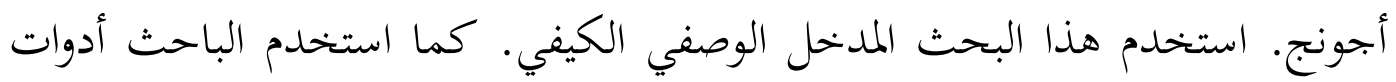

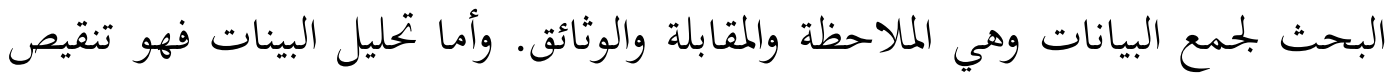
البيانات، وتقديم البيانات، واثبات البيانات بمقارنة الثابت. ولتفتيش صحة البيانات يعمل الباحث تطويل أوقات الحضور والتثليثي والمناقشة مع بعض الإخوان.

ودلت نتائج هذا البحث على أن أهداف التعليم التعبير التحريري باستراتيجية التعلم التعاوين تستخدم الخطوات منها تعيين المعلم الأهداف والمواد ووسائل التعليمية ثم تعيين إجراءات التعليم بتقسيم الطلبة في ست بحموعات، فيعد المعلم قراطيس العمل للطلبة مع ألوان مختلفة لكل بحموعة، فيوزعها على كل بحموعة. بدأ طالب من المجموعات

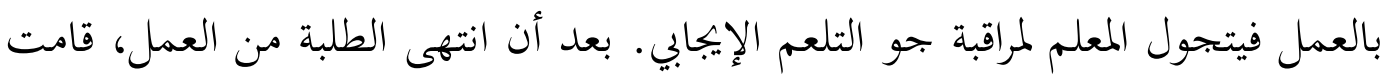
كل بحموعة بالمناقشة حول عملهم أمام بجموعة أخرى، ثم بعد ذلك قام المعلم بالتقويم على أعمال الطلبة. واستخدام استراتيجيات التعلم التعاوني له أثر كبير عند الطلبة في

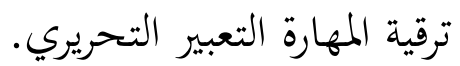

الكلمات الأساسية: استراتيجيات، التعلم التعاوني، التعبير التحريري. أساسيات البحث

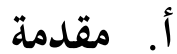

الكتابة إحدى المهارات اللغوية الأريع التي لابد أن تقوم بها الطلبة لترقية كفائتهم

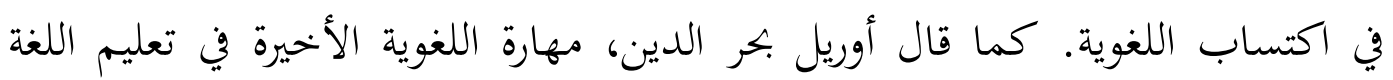


العربية هي مهارة الكتابة. بل في بحال الأكادمية خاصة بمستوى الجامعي، أهمية هذه

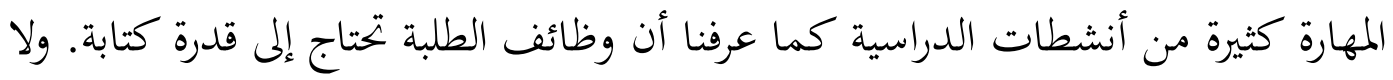
سيما لكتابة بحث العلمي، ورسالة الماجستير، ورسالة الدكتوراة (أوريل بحر الدين، .$(I V V: Y \cdot$. IV فأما الكتابة يتعلق بالتعبير كإفصاح الإنسان بلسانه أو قلمه عما في نفسه من الأفكار والمعاني. تقسم التعبير إلى قسمين، القسم الأول مرتبط بالشكل، والثاني مرتبط بالغرض. ينقسم التعبير من حيث شكله إلى قسمين هما التعبير الشفهي والتعبير

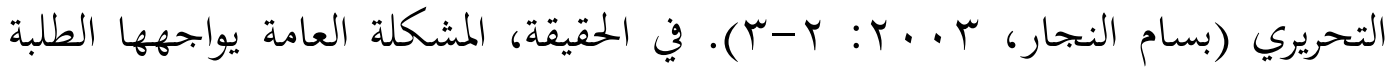

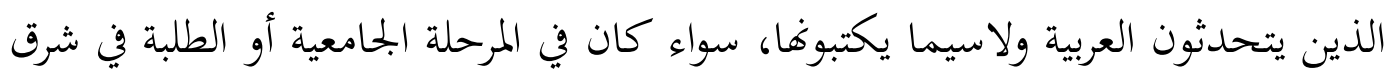

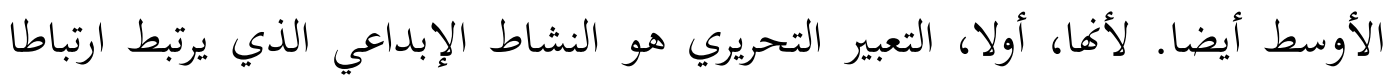

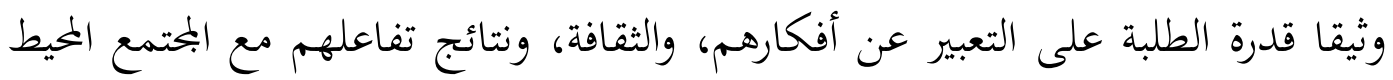

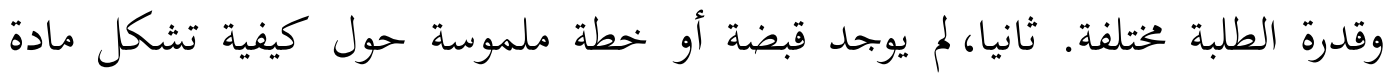
التعبير التحريري. ثالثا، جمع التعبير التحريري بين قدرة الطلبة على تطبيق قواعد النحوية

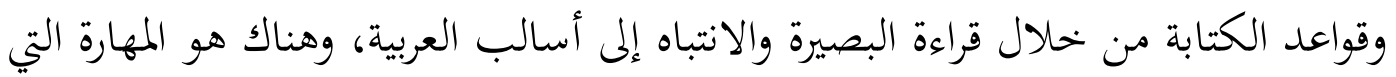

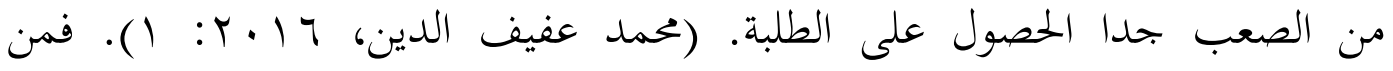

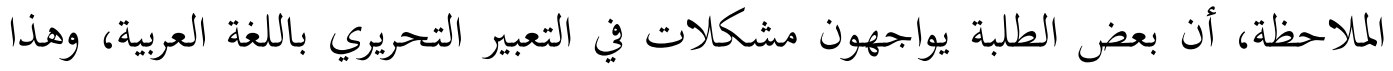

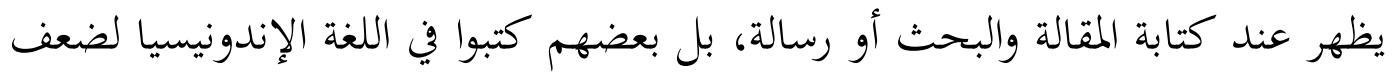
الاستعاب على هذه المهارة. ومن المشرفين الذين يشرفون على كتابتهم يشتكون من قدرة الطلبة في التعبير التحريري باللغة العربية. فإن هذا الأمر يدل على كفاءة الطلبة ضعيفة كليفة في مهارة الكتابة لم تكن فعالا. في تعليم اللغة العربية، ستكون الفعال إذا كان استراتيجية التي تقوم بها المعلم

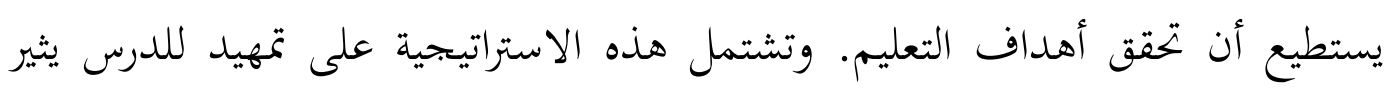

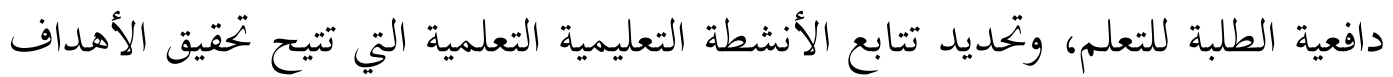


المرجوة، بما تتضمنه تلك الأنشطة من تحديد لأدوار المشاركين فيها (المعلم، الطلبة)

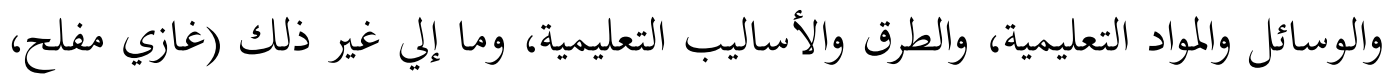

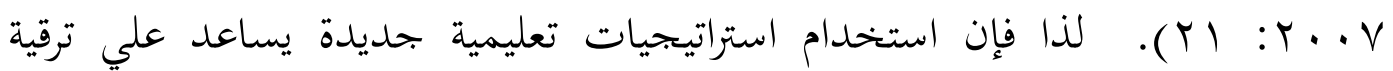

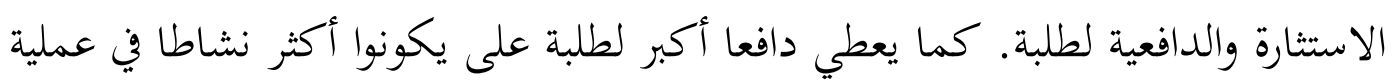
التعلم كما يؤدي إلى تبادل الخبرات والمهارات المختلفة بينهم.

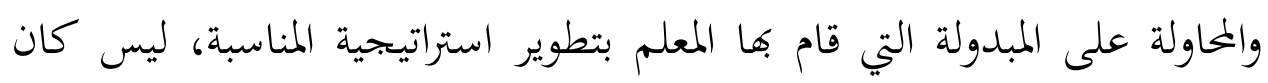

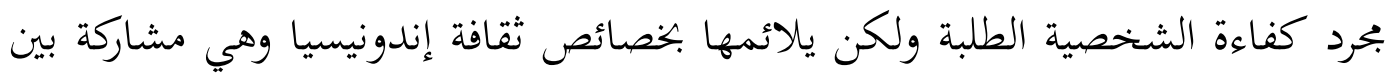

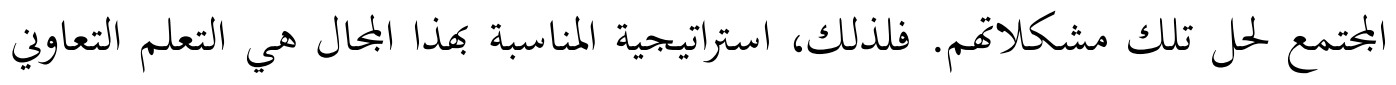
الذي يعرض العمليات اللغوبية منها في تدريس مهارة التعبير التحريري بخصوصه أنه يفضل وظائف اللغة في استخدامها المتعلق بموقف التعاوني. وهذا المدخل ذو أهمية كبيرة لمساعدة المعلم على إيجاد جو إيجابي وعلاقة وثيقة بين الطلبة خلال القيام بالمهمة

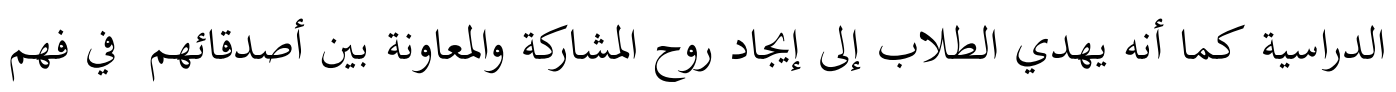

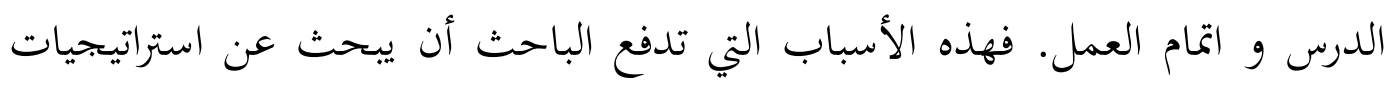

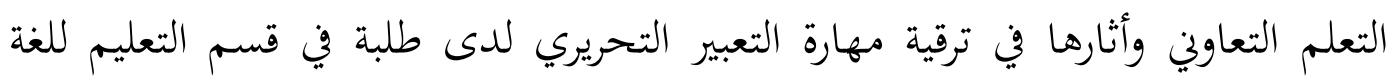
العربية بجامعة الإسلامية الحكومية تولونج أجونج.

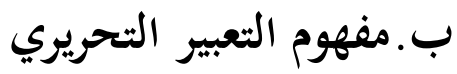

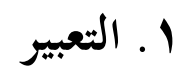

والتعبير في الإصطلاح هو إفصاخ الإنسان بلسانه أو قلمه عما في نفسه

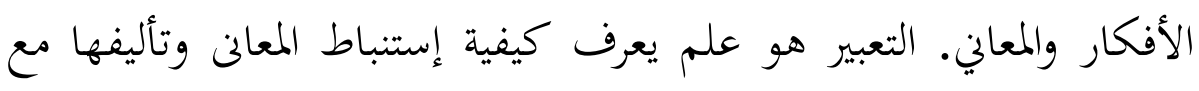

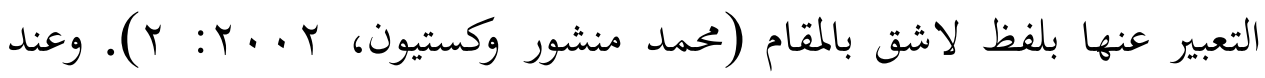

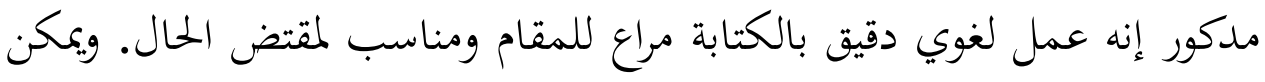


تعريفه إجرائيا بأنه القدرة على السيطرة على اللغة كوسيلة للتفكير والتعبير

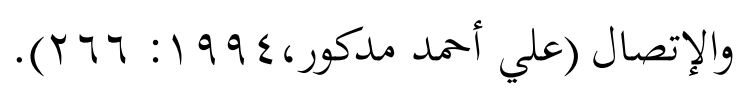

قسم الباحثون التعبير إلى قسمين، القسم الأول مرتبط بغرض، والثاني

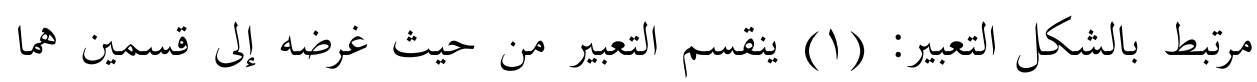

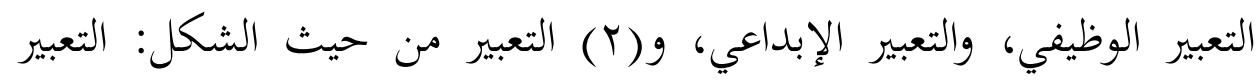

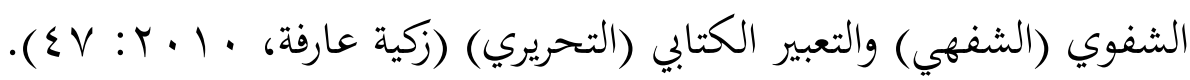

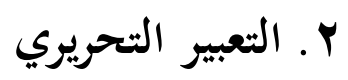

والتعبير التحريري هو وسيلة الاتصال بين الفرد وغيره من تفصله عنهم

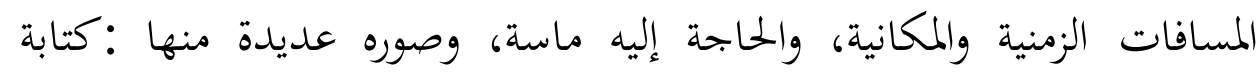

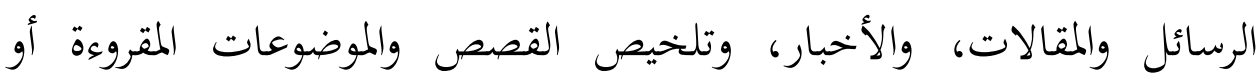
المسموعة، وتأليف القصص، وكتابة المذكرات، والتقارير، واليوميات، وغيرها

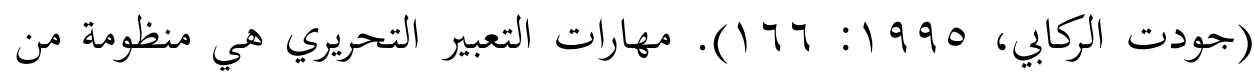

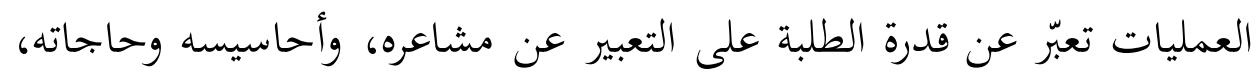

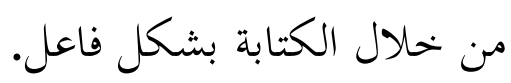

\section{r. استراتيجيات في تدريس التعبير التحريري}

أما تقنية التعليم التعبير كما قال أحمد فوأد ايفندي أن طريقة التعليم اللغة التحري الحديثة، تعليم اللغة بمثابة الدعم لتحقيق المهارة القواعد اللغة. القواعد اللغة

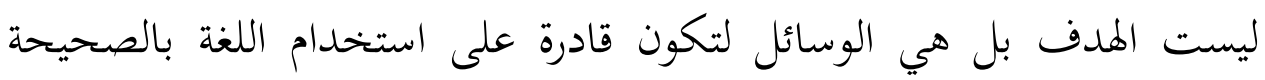

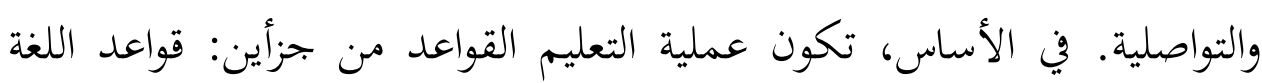
(النحو والصرف)، وتوفير التدريب (Drill). 
طريقة التدريب هي بعض المقاربة التأكيد على ضرورة تقديم النحو

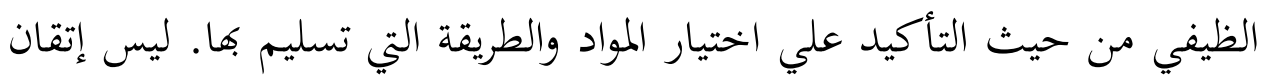

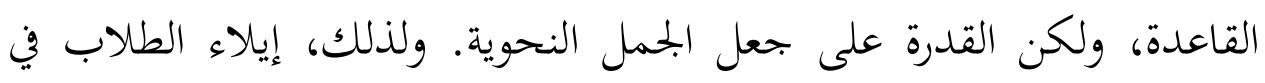

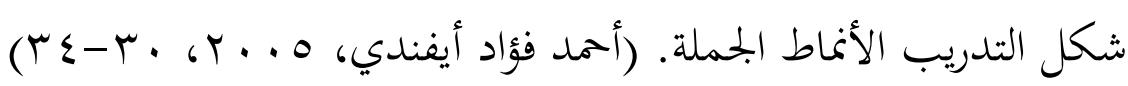

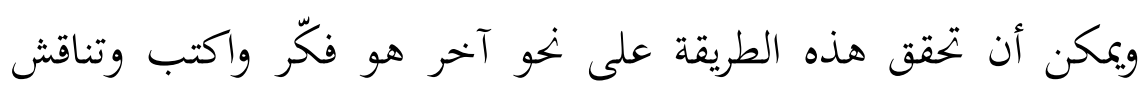

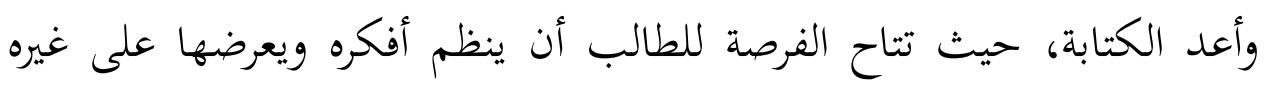

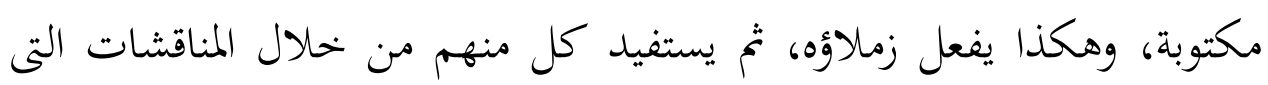
تدور في كل موضوع، ثم يعيد كل طالب ما سبق أن كتبه على نحو أفضل.

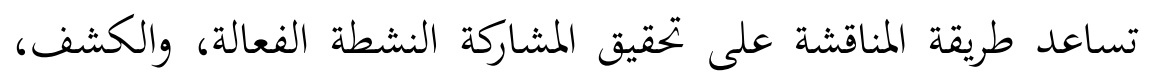

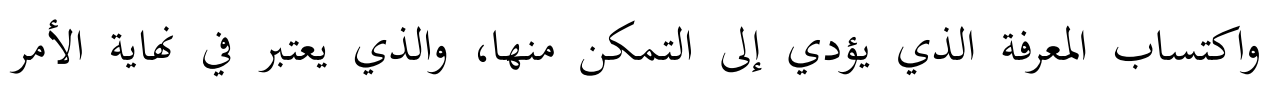

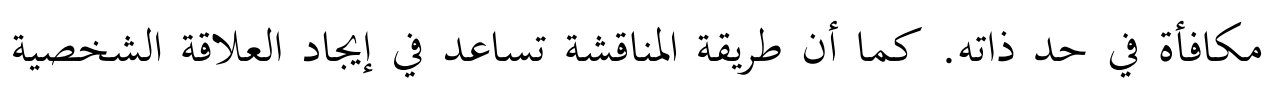

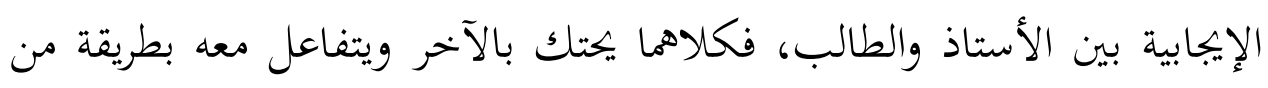
شأها أن توجد الثقة والاحترام المتبادلين بينهما.

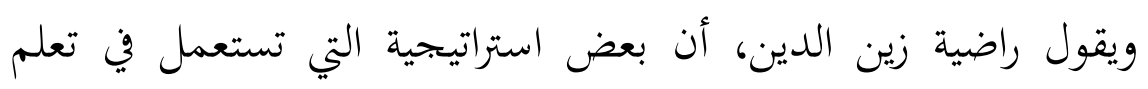

$$
\text { وتعليم الإنشاء هي: }
$$

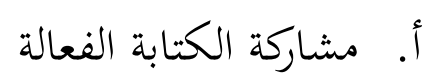

هي استراتيجية حيث بتعل الطلاب يعبرون آراءهم في الكتابة.

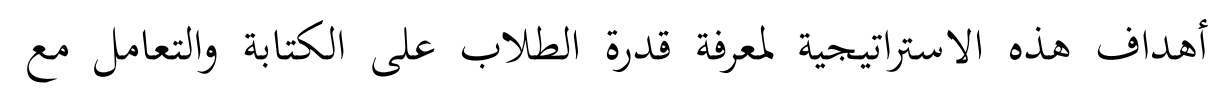

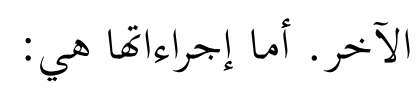

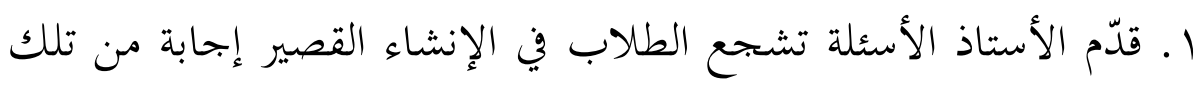
الأسئلة. مثل: ماذا تفعل في المواقف الآتية أ) ستذهب إلى رحلة لمدة ثلاثة أيام مع الأصدقاء. ب)طلب صديق لك أن تساعده في بعض المسائل وأنت مشغول. 
ج) وصلتك بطاقة تهنئة بعيد الفطر من خالك.

r. أجاب الطلاب وطوّروا إجابتهم على شكل الفقرة.

r. وأمرهم الأستاذ أن يتعاونوا بينهم في إجابة الأسئلة والتعبير عنها.

ع. ثم مناقشة تلك الإجابات والكتابات من ناحية المضمون والتراكيب

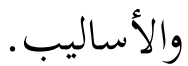

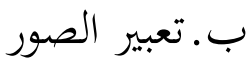

هذه استراتيجية أن يكون الطلاب يعبرون قصص الصور منظما. أما

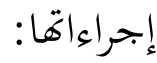

ا ـأعدّ الأستاذ الصور المناسيب بموضوع التعليم.

r.تحديد الطلاب الصور تعبيره منظما في زمن مؤقت.

r.قرأ أحد الطلاب والآخرون يستمعون وينقدون كتابته.

ج· مفاهيم رئيسية

هي لتلخيص مضمون نص القراءة ثم التعبير في الكتابة والتلخيص على

شكل الصورة أو الجحداول عن المفاهيم المتعلقة بموضوع الناص. أما إجراءاتها:

ا ـ اختار الأستاذ الموضووع ونص القراءة.

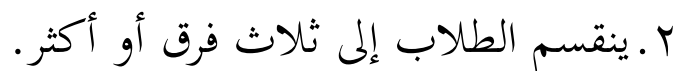

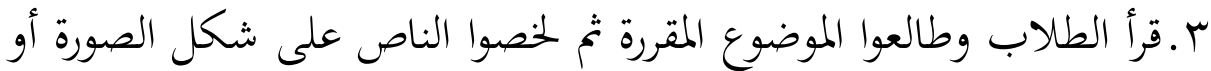

$$
\text { ع ـوعرض كل فرقة ماكتبه. }
$$

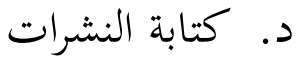


يمكن استخدام هذه استراتيجية بعد تقديم المادة التعليمية. أهداف استخدامها هي لأن يهتم الطلاب الدرس وأن يكونوا إيجابين، وبهذه الاستراتيجية يمكن الأستاذ أن يعرف فعالية التعليم. أما إجراءاتها:

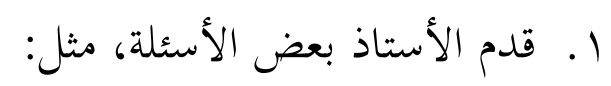
أ) هل فهمت هذا الدرس؟ ب)ماذا تعلمت من هذا الدرس؟

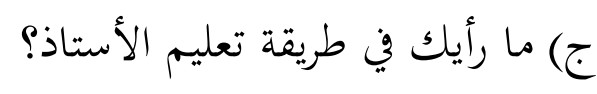

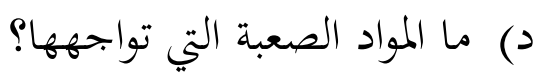
هـ هل عندك اقتراح وتعليق؟

r. فكتب الطلاب ما قد تعلموا وفهموا من المادة التعليمية المقدمة على ولى شكل تقييم عملية التعليم والتعبيم أو الاقتراح والتعليق. r. بم مناقشه تلك الكتاب جماعة.

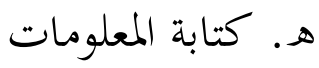

هذه استراتيجية تستخدم لترقية انتباه الطلاب على المشكلات البشرية

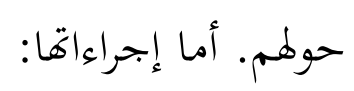

ا.كتب الطلاب المعلومات حول المشكلات البشرية من المجلات، أو الجرائد، أو التلفزيون، أو ملاحظتهم على حقائق الحياة البشرية.

$$
\begin{aligned}
& \text { r. ففكروا في حل تلك المشكلات. } \\
& \text { r.ثم كتبوا على شكل المقالات. } \\
& \text { و. انعكاس الموضوع أميول } \\
& \text { أما إجراءاتما: }
\end{aligned}
$$


1. أعدّ الأستاذ الصورة أو أخذ الطلاب إلى مكان مناسب بالموضوع

$$
\text { المدروسة. }
$$

r. أمر الأستاذ الطالب أن يلاحظوا الموضوع المقررة مما حوله ملاحظة

$$
\text { مباشرة. }
$$

$$
\text { ز. مأم مذاكرة مواجهة كتب الطلاب من ملاحظتهم منظما. }
$$

1. قرأ الأستاذ الناص أو حداث الطلاب موضوعا، وهم يستمعون ما قرأه

$$
\text { الأستاذ. }
$$

r. يمكن الطلاب أن يكتبوا الأسس الرئيسية من تلك القراءة أثناء

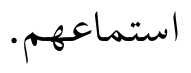

r. بعد استماعهم الأستاذ، كتبوا بما استمعوا وفهموا في دفاترهم وعبروا عنه.

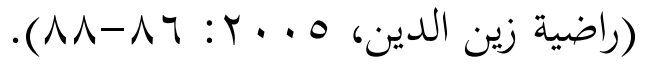

ويمكن استخدام عدد من أساليب التعليم اللغوي الحديثة في هذا المحال،

$$
\text { أ. استراتيجية الغلق والتنويع الحلول }
$$

حيث يطلب المدرس من الطلاب في أثناء قراءقم لقصة ما تغيير

موقف أو حدث من أحداث القصة، ثم تطلب منهم إعادة كتابة القصة بناء

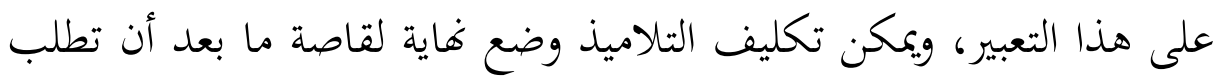
منهم التوقف عن قراءما قبيل نهايتها. وتتمي هذه الإستراتيجية مهارة الأصلة، ومهارة المرونة، ومهارة الطالاقة التعبيرية. ب. - (إستراتيجية التحويل 
يقوم القارئ وفق هذه الإستراتيجية بعد استعاب النص القرائي، سواء

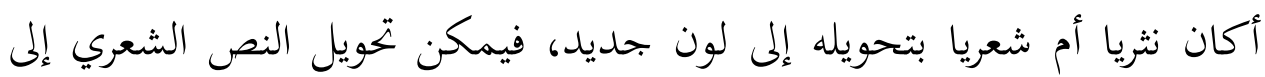

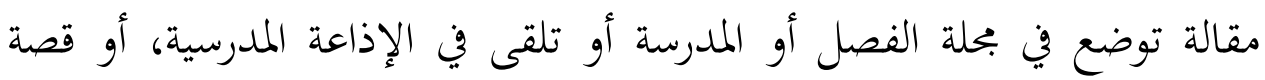
تحكى على مسامع الطلبة في أوقات النشاط، والقصة إلى مسرحية تمثّل، أو لوحة

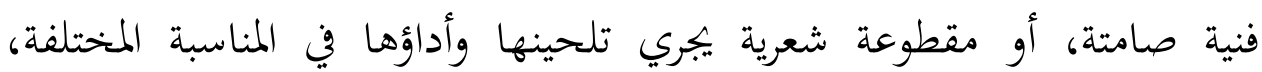
وهكذا.

وتساعد هذه الإستراتيجية على تنمية مهارة الأصلية، والتوسع، وتلائم هذه الإستراتيجية طلبة الصفوف الأخيرة. ج· إستراتيجية التعمق

حيث يمكن للمدرس تكليف الطلبة بعد قراءة قصة معينة وضع أكبر

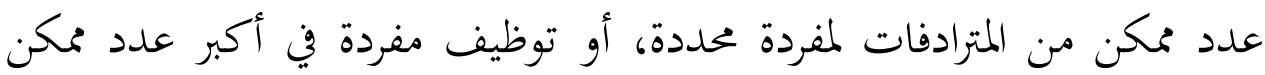

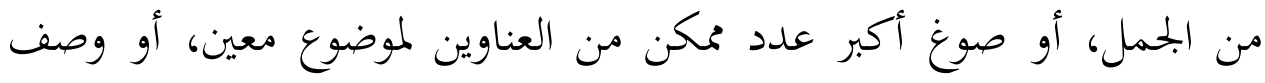
شخصية ما في القصة بأكبر عدد ممكن من الصفات. وتنمي هذه الإستراتيجية مهارة الطلاقة اللفزية، ومهارة التوسع، وهي مناسبة في دروس القراءة التي تدور حول حدث أو قصصي، ودروس المطالعة بمختلف صفوف الحلقة العليا. د. إستراتيجية تنمية التخيل.

حيث يطلب من المتعلمين توظيف بعض المفردات والتراكيب في تأليف قصة أو مسرحية بسيطة تقوم على الحواربين أشخاص حددهم المدرس، ويمكن

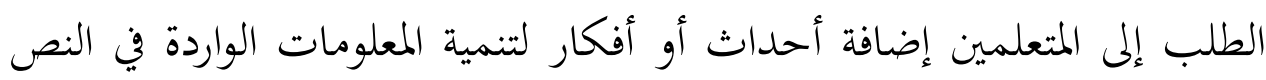

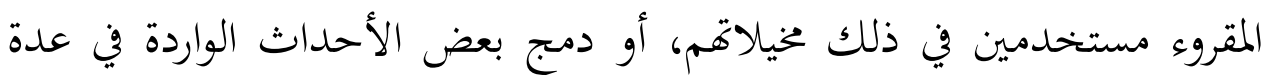
قصص لتأليف قصة جديدة، أو استثمار بعض الصور لتأليف قصة تربط بينها. 
وتساعد هذه الإستراتيجية على تنمية مهارات الأصالة، والطلاقة التعبيرية، والتوسع، ويمكن استخدام هذه الإستراتيجية في مختلف النشاطات النسات

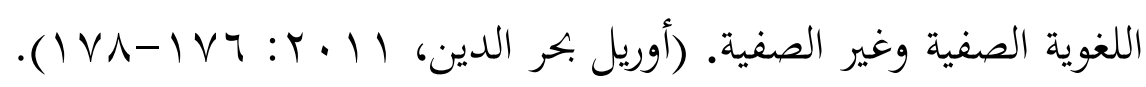

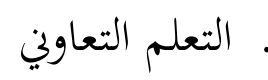

بدى التعلم التعاوني من الافتراض بأن الطلاب سيحصلون النظرية الصعبة و

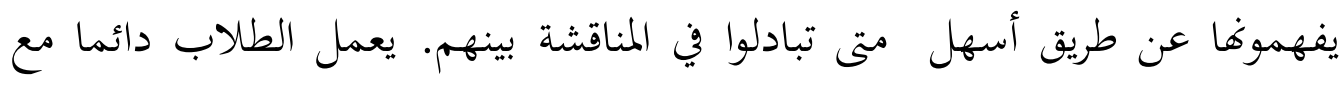

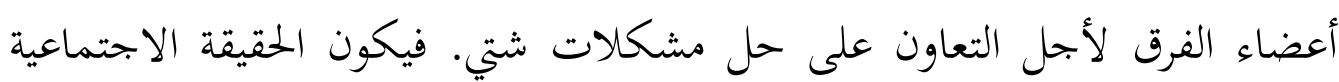

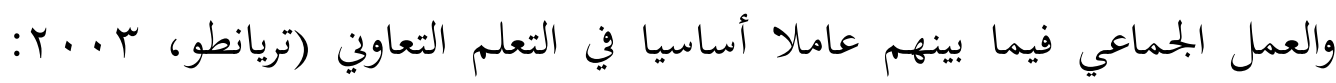

$$
\text { أ. مفهوم التعلم التعاوين }
$$

كان المصطلح " التعلم التعاوين" مشتقا من cooperative بمعنى القيام بعمل مع فريق على سبيل المعاونة والمعاضدة بين أعضاء الفريق أو الفئة. يرى جونسون حيث نقله إسجوني في كتابه "Cooperative Learning

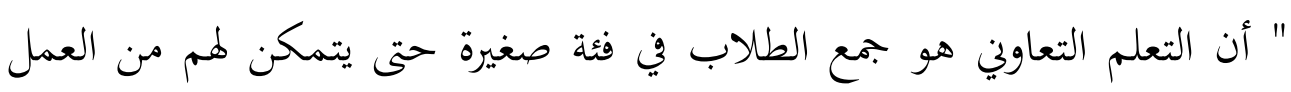
الجماعي بقدرقم التامة و يتعلم بعضهم بعضا في تلك الفئة (إسجوني، 9 . . ب ب:

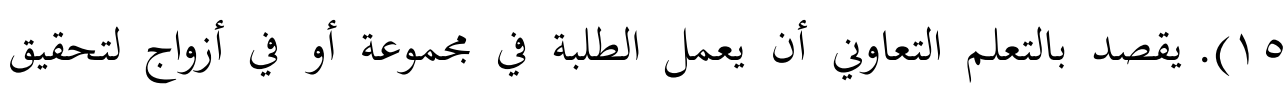

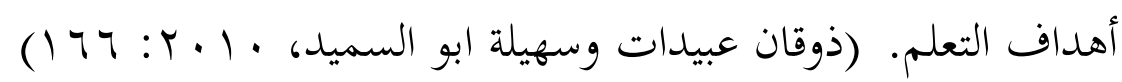

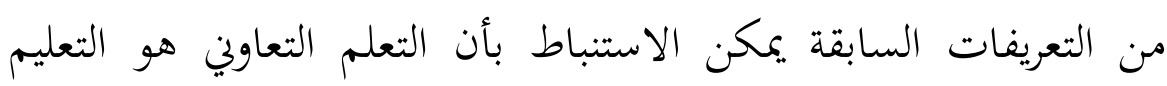
الذي يجعل النظرية الصعبة سهلة عن طريق العمل الجماعي ويسير التعلم بجمع

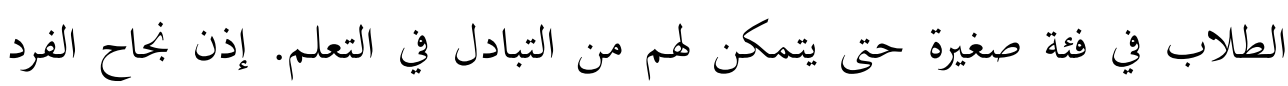
يتعلق بنجاح الفئة والعكس. 
وأما الغرض الأمامي من تطبيق التعلم التعاوني فهو امكان الطلاب من

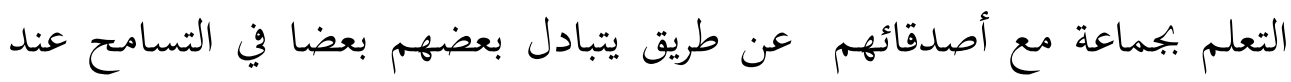

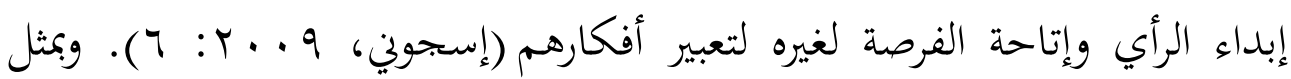
هذا النموذج من التعليم يكون للطلاب الذين لم يفهموا الدرس جيدا فرصة للتعلم

$$
\text { ب.عناصر التعلم التعاوني المتوفين. }
$$

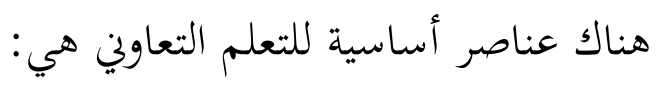

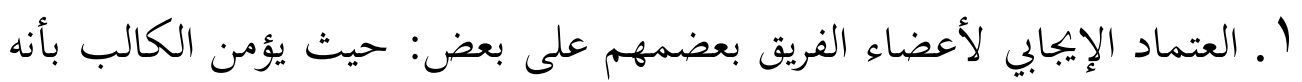

$$
\text { مسؤول عن النجاح البمموعة ككل. }
$$

r. التفاعل وجها لوجه: على اعتبار أن الطلاب في حاجات إلى التفاعل عضويا.

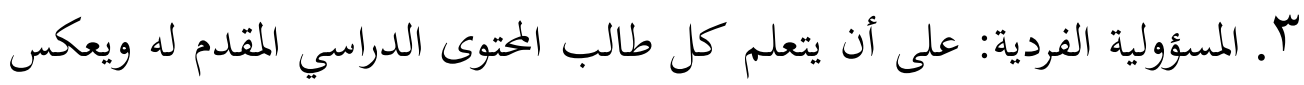
تمكنه من المادة فيما بعد، أي أن الفرد يعتبر مسؤولا عما يعهد إليه من أعمال.

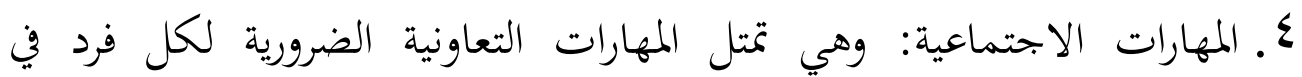

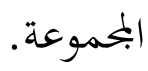

0. متابعة مهام البحموعة وتقويم الأداء: وتعني التغدية الراجعية لتحسين الأعداء

$$
\text { ج. الخطوات العامة لتعلم التعاوني. }
$$

1. ـ مناقشة الطلاب/الطالبات في الجلسة الأولى للحصّة بفوائد التعليم التعاوين.

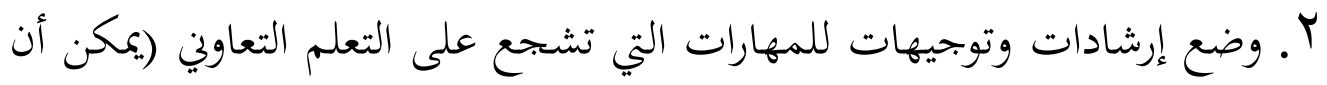

$$
\text { r. تشكون على شكل ملصقات أو شعارات) }
$$

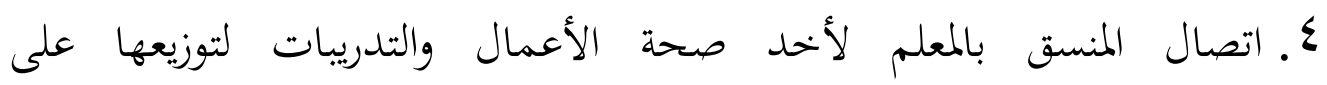

$$
\text { زملائه/زميلاتما. }
$$


0. قيام قائد/قائدة البحموعة بتوزيع المهمات على الأعضاء مع مراعة الإرشادات

الواردة.

7. بعد إبناز صحيفة رقم (1) يقوم المنسق/لمنسقة بإحضار بطاقة التصحيح

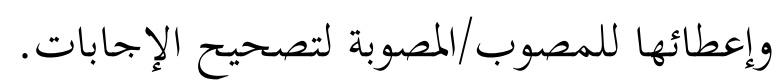

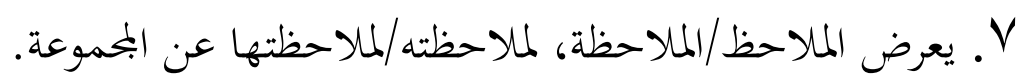

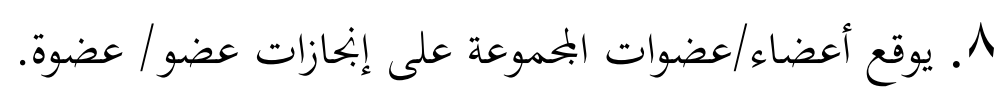

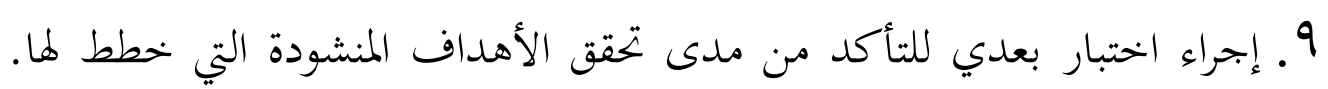

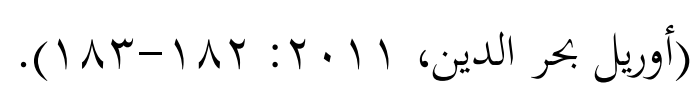

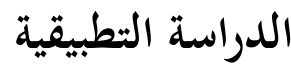

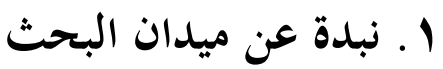

قبل أن يصبح القسم، التعليم اللغِة العربية هي احدى من الشعبة في

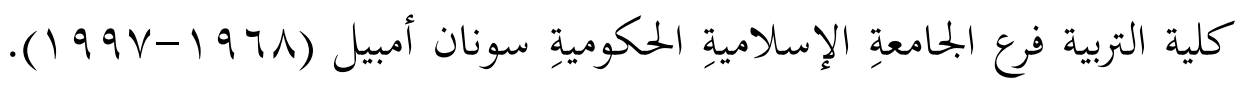

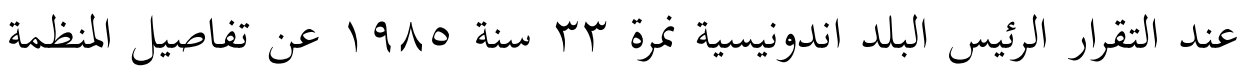

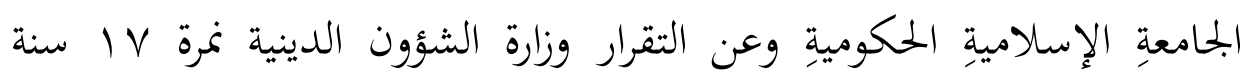
1911 أعطي تلك المؤسسة الحقوق لفتح برنامج درجة السرجانا الأولى المانل باستخدام حصة (SKS). في ذلك الوقت، ملك شعبتان، هما: شعبة التربية الإسلامية وشعبة التربية اللغة العربية.

كما جهود الحكومة لتطوير مؤسسات الجامعة الإسلامية، بخاصة

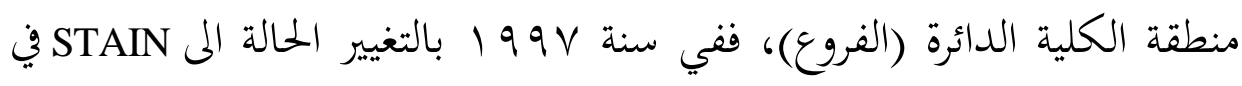




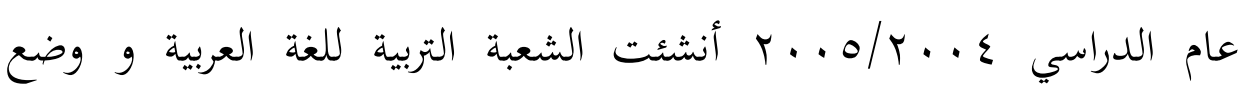

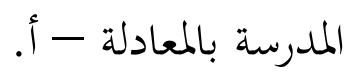

في السنة ع ا.ب، تغيير هذه الجامعة درجتها الى IAIN حتى الآن. فلذلك، يصبح التعليم اللغِة العربيةٍ شعبتا في كلية التربية وعلوم التربوية (FTIK). وإحدى من أهداف هذه الشعبة هي استعاب طلبة المهارات اللغوية تطبيقا

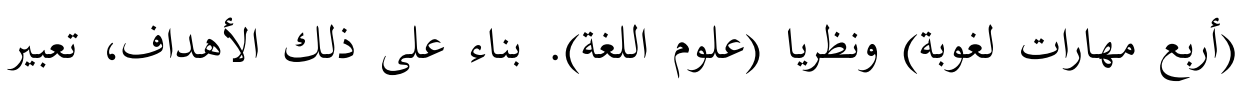

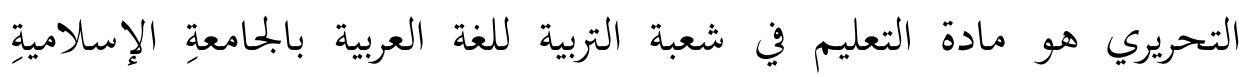

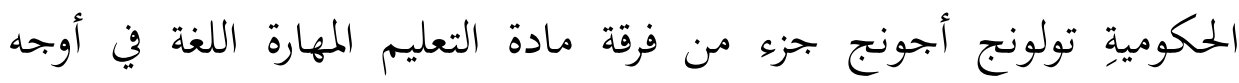

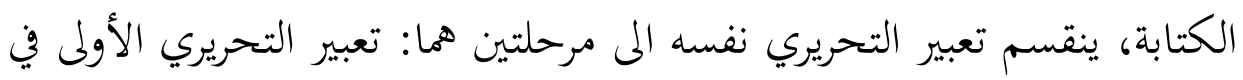
مرحلة الثالثة وتعبير التحريري الثانى في مرحلة الرابعة.

r. استراتيجيات تعلم التعاوني في ترقية مهارة التعبير التحريري لدى طلبة

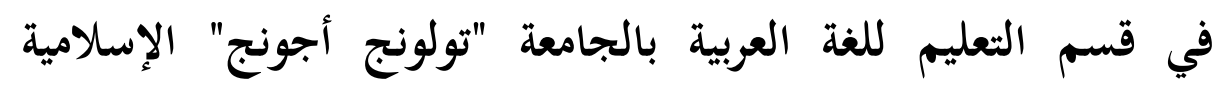

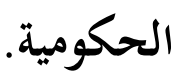

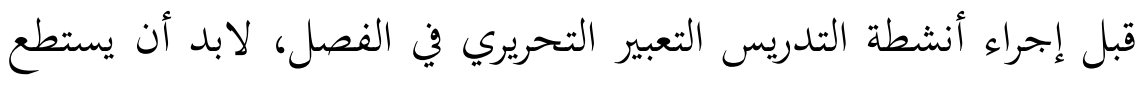

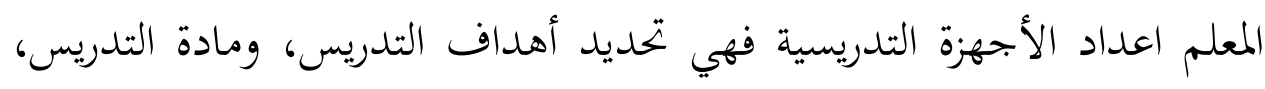
واعداد التقويم التدريس، وتأليف الخطة الدراسية المناسبة بحالة قسم التعليم للغِّة العربية بالجامعِة الإسلامية الحكوميةٍ تولونج أجونج.

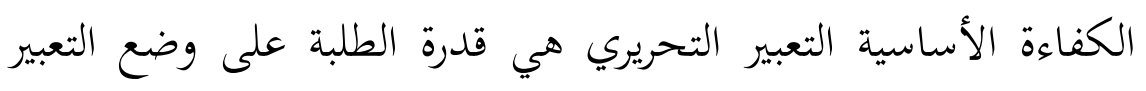
الوصفي مع أن يوافق التعبير القواعد اللغوية والعبارات الاصطلاحية الشائعة.

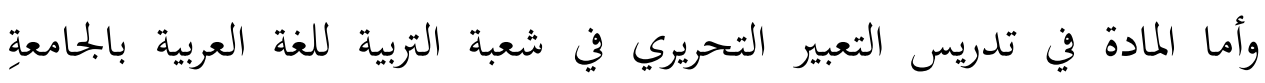

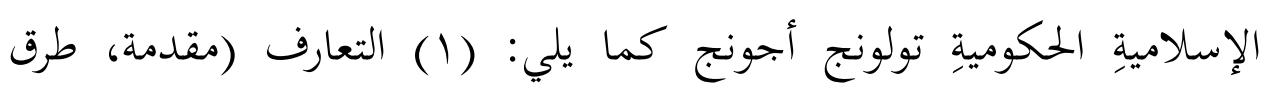

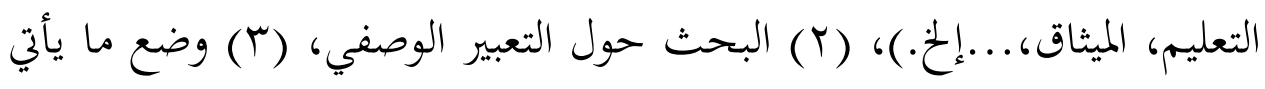


اللجملة المفيدة بحيث لاتقل عن عشر كلمات (و أما......ف...... ينبغي

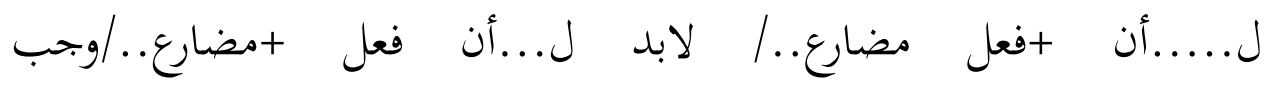

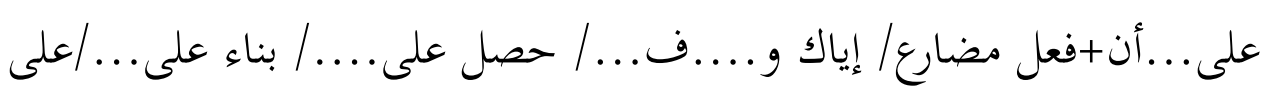

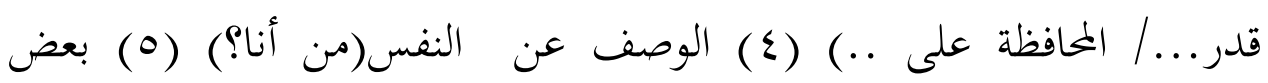
الاصلاحات. الوصف عن النفس (من أنا) (I) الوصف عن وسائل التعليمية

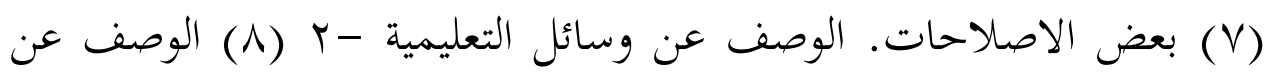
الطريقة وأنواع الطرائق التعليمية (بلغة الطلاب)، (•) (1) بعض الاصلات الاصلاحات.

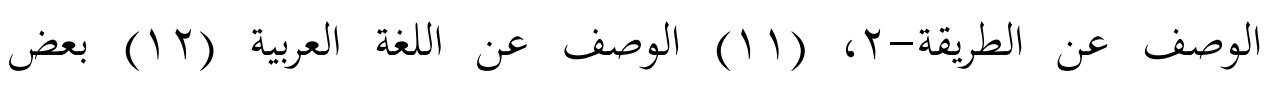
الاصلاحات. الوصف عن اللغة العربية

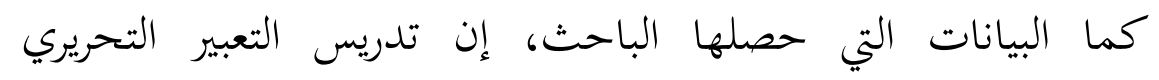

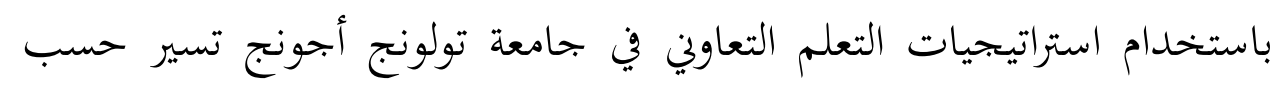

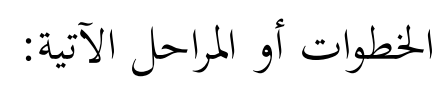

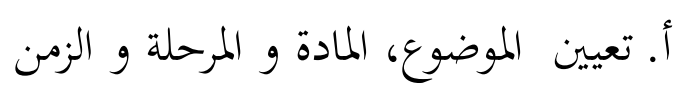

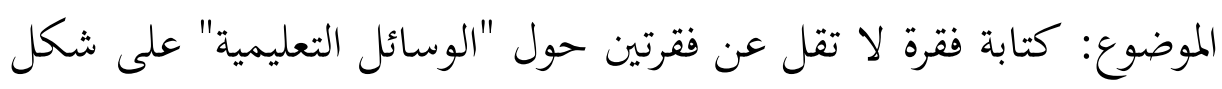
البحلة الحائطية

المادة: التعبير التحريري r المرحلة: الرابعة - ب الزمن المحدد: •ـع دقيقة

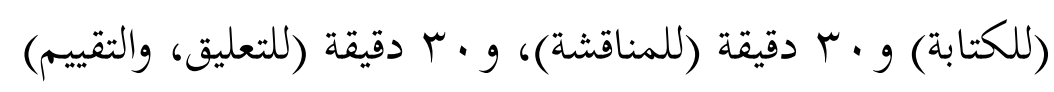
ب. تعيين أهداف الدرس (الكفايات المطلوبة)

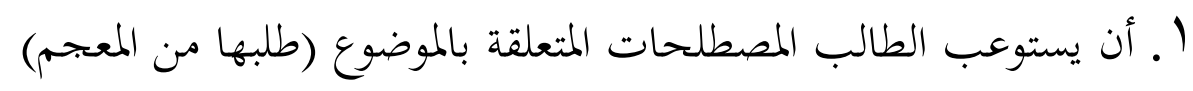

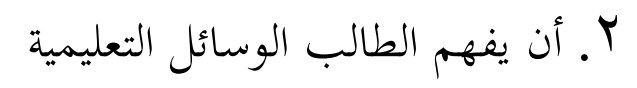
؟ أ. أن يعرف الطالب الفوائد الوسائل التعليمية ع. أن يميز الطالب الأنولع الوسائل التعليمية 
قدرته على وضع الفقرة وفقا بقواعد علوم اللغة (الاملاء، النحو،

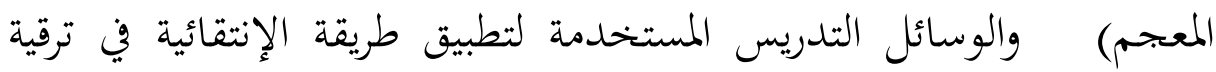
مهارة التعبير التحريري كما يلى: الأوراق من وظيفة الطلاب، والسبورة، والأجهزة (LCD)

لتطبيق استراتيجيات المستخدمة المعلم في ضوء التعلم التعاوني في

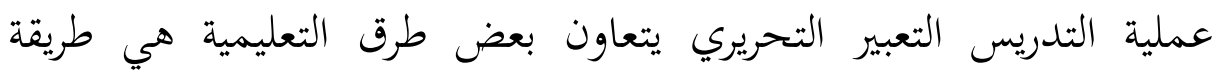
القواعد والترجمة، والتكراري/التدريبي بشكل التوطيفي، وطريقة المناقشة. وأما إجراء العملية التدريس التعبير التحريري في قسم التعليم للغة العربية بهذه

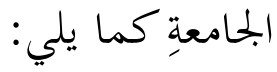

أ. قبل أن يجراء جوهر التدريس التعبير التحريري، يبدأ المعلم بالتحية ويسأل الطلاب عن خبرها وتحقق الحضور من الطلاب بكشف الحضور.

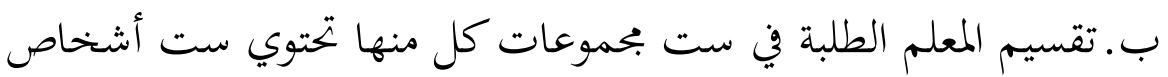

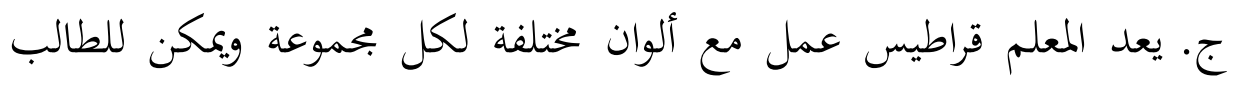

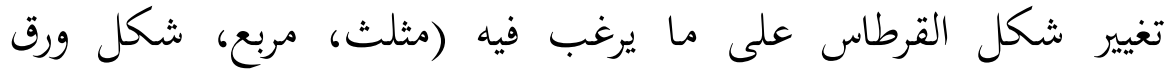

$$
\text { (الشجر، مستدير) }
$$

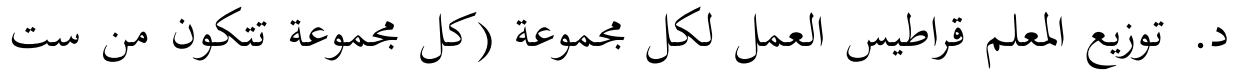
أنفار حيث نفران منهم يضعان الفقرتين حول مفهوم الطريقة التعليمية، ونفران آخران يضعان الفقرتين حول فوائد الوسائل التعليمية، والآخران يضعان الفقرتين حول أنواع الوسائل التعليمية).

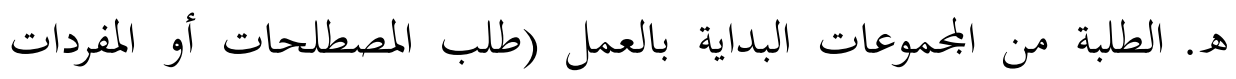

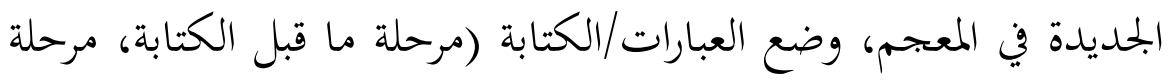
الكتابة كيف ماكانت دون ترتيب منتظم، مرحلة المراجعة، مرحلة التحرير، 
مرحلة النشر: هنا يمكن للطلاب الاهتمام بالأمور الثنائية المهمة مثل تشكيل القراطيس وتنظيم حجم الحروف وعرض الطرف اليمين واليسار للقرطاس وغيرها ما يتمكن من اتيان شيئ يسرّ القارئين والناظرين)

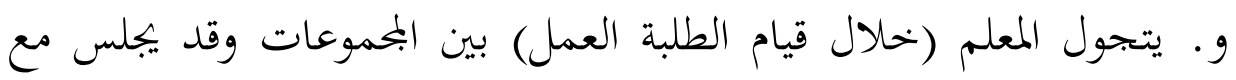
مجموعة إذا وجدها في حاجة إلى مساعدته.

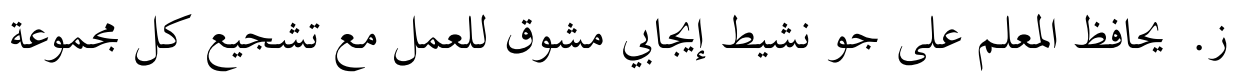
بالمشاركة وعدم الضوضاء.

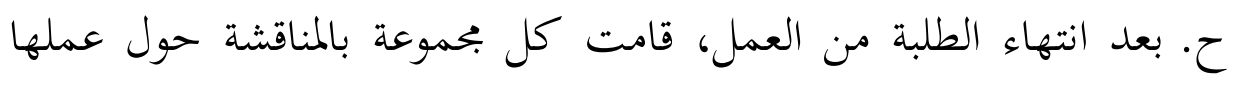

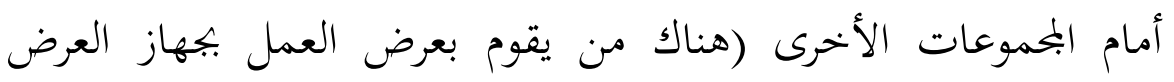
البعض الآخر بتعليقه على سبورة)

ط. تقييم المعلم أعمال الطلبة (الأمور المطلوبة في التقييم: الجمال، النظافة،

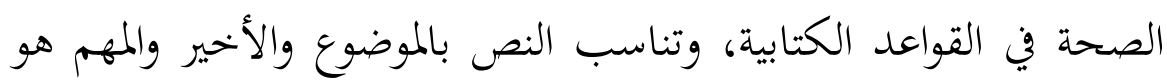
المشاركة عند العمل). وعندما لا يمكن للمعلم تقييم صحة الكتابة في

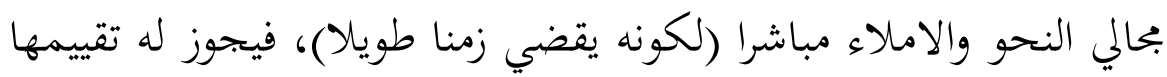

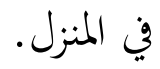

بناء على البيانات أعلاه التي حصل الباحث بملاحظة والمقابلة، أن

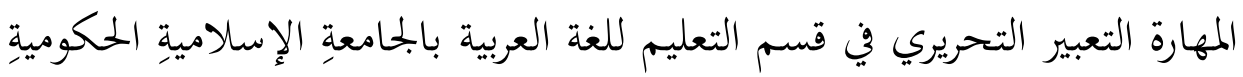

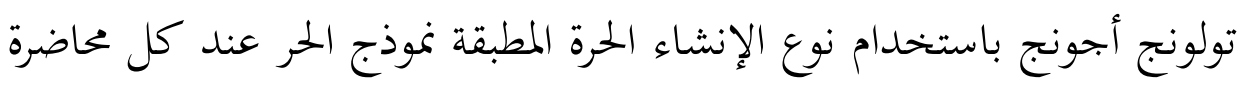

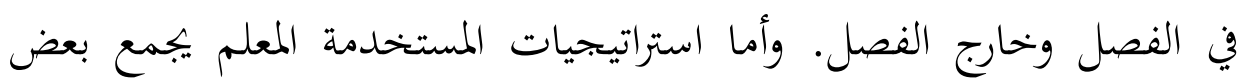

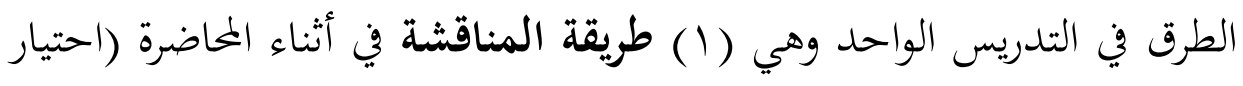

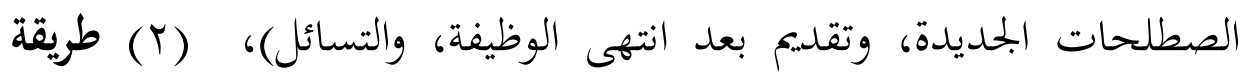

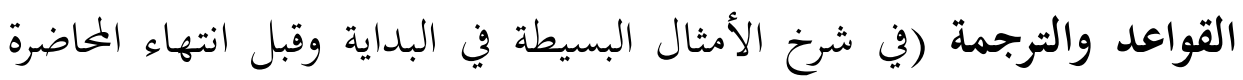


لتصحيح الأخطاء)، (r) طريقة النكراري (في أثناء المحاضرة حين ما يكتب الفقرة في القرطاس الموزع وفي السبورة).

ومن الملاحظة التي تجري الباحث عن خطوات التدريس التعبير

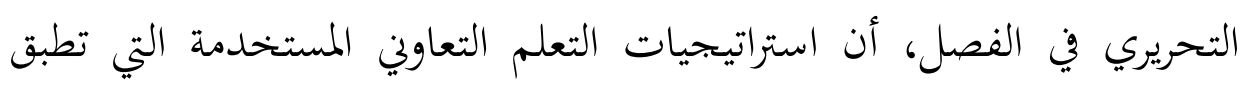

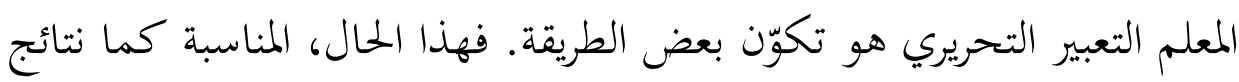

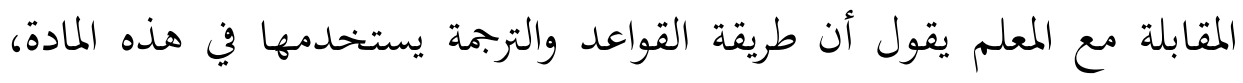

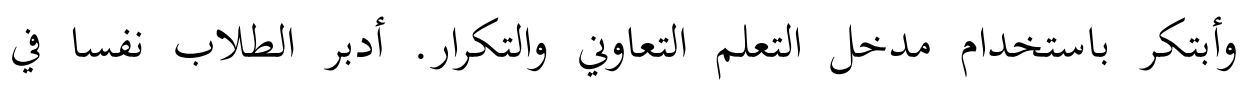
الفصل والطريقة التكرار عند تصنع بحلة الجدارية والمحلات فرقتا.

في العملية التدريس تحتاج التقويم لتقييم بقدر ما الكفاءة الطلبة في

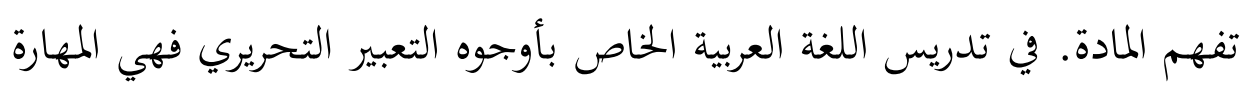

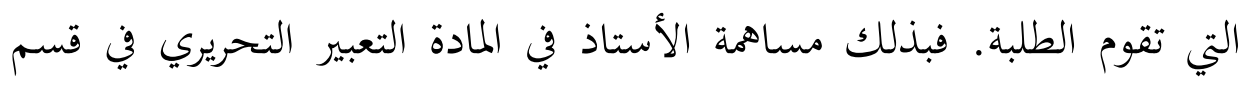
التربية للغة العربية في التقييم نتيجة تدريس الطلاب محتاج لترقية جودة التربية.

يقول المعلم أنه لقيمة إمتحان النصفي، أخد من وظيفة النفسية الطلبة

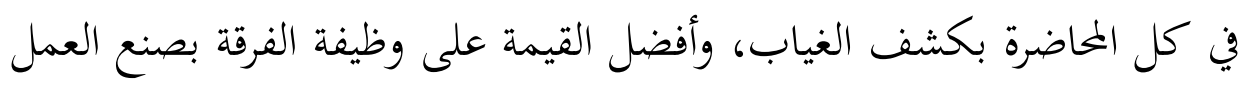

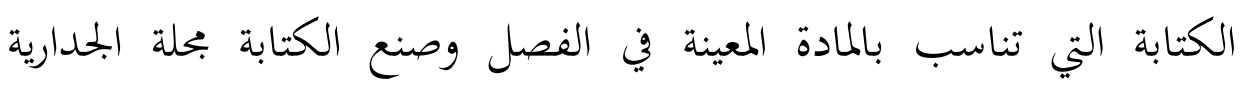

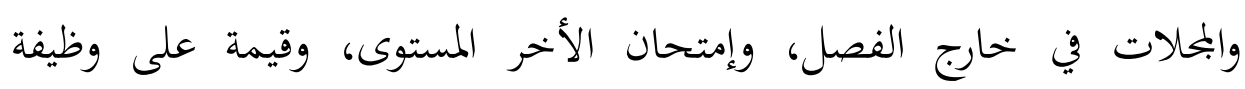
النفسية.

r. أثار استراتيجيات تعلم التعاوني في ترقية مهارة التعبير التحريري لدى

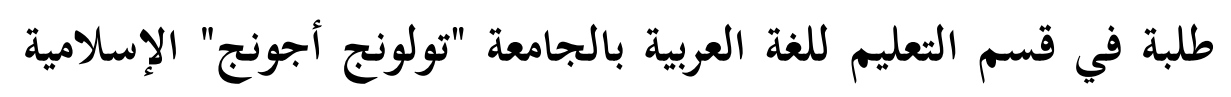

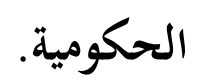

أهداف التعبير التحريري من خلال هذه المهارة يتمكن الدارسين من : 
أ. كتابة الحروف والكلمات والحمل والفقرات بخط واضح طبقا للقواعد الإملائية وقواعد اللغة وعلامات الترقيم الصحيحة مع الاهتمام أيضا بعلم

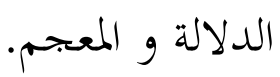
ب.تكملة الجمل والفقرات باستخدام الكلمات والعبارات والحكم ولأمثال المناسبة كتابيا. ج. كتابة الجمل بأسلوب صحيح المصوغة بنوعيها الخبري والإنشائي . د. مل ملء الاستمارات المعينة بالمعلومات المطلوبة الصحيحة كتابيا . هـ. كتابة الأفكار الرئيسية من المواد المسموعة والمقروءة. و. كتابة الإنشاء مستعينا بلأفكار الرئيسية المسجلة.

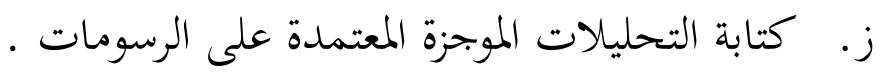

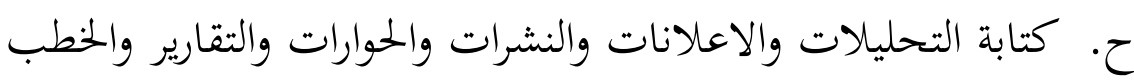
ط. كتابة الرسائل الرسمية و التهيئة والتعذير

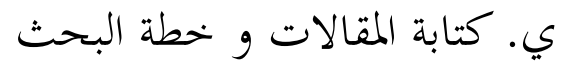

ولكن التعليم لايزال يرتكز عادة في أمر وضع الجمل والفقرات زعما

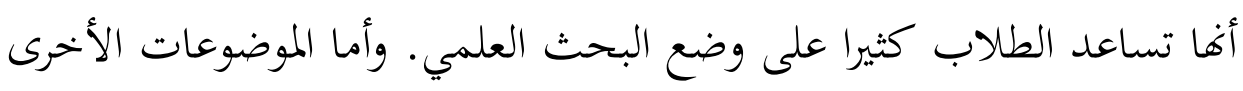

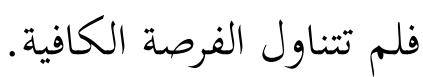

تناسب بتلك الأهذاف، استخدام استراتيجيات التعلم التعاوني لها أثر

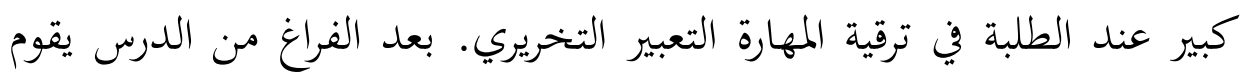

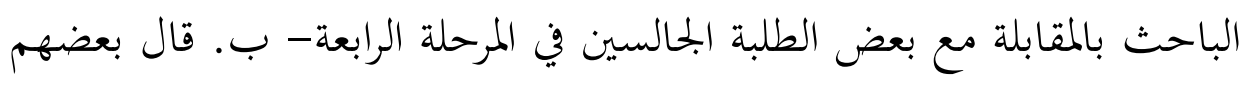

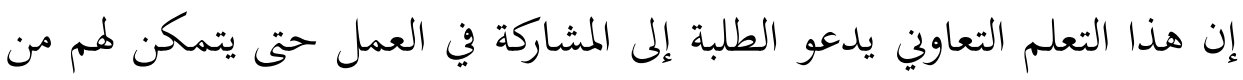

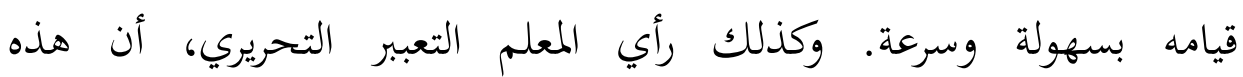

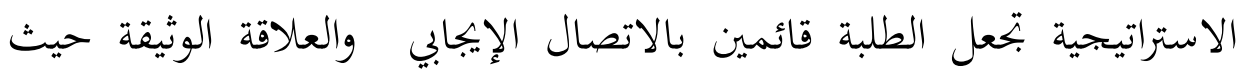




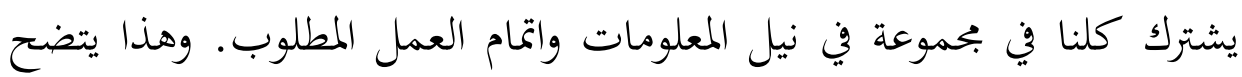

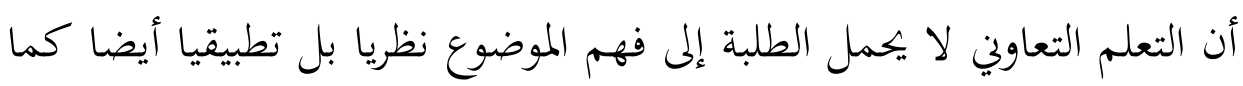
أنه يهديهم إلى ايجاد العلاقة القوية بينهم.

وبالإضافة على ذلك، أثار استخدام اسنراتيجيات التعلم التعاوين

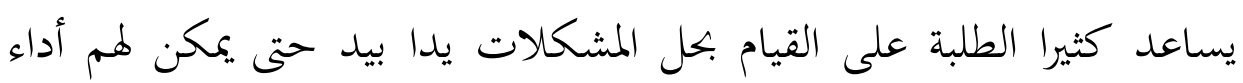

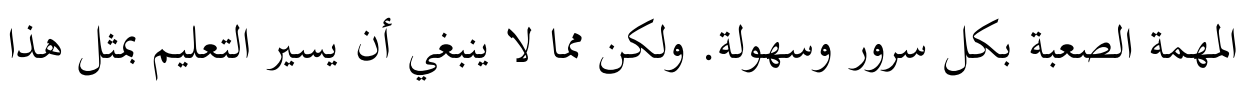
الشأن على الدوام، لأنه يقضي أوقاتا طويلة حتى لا يستطيع بعض الطلبة اتمام

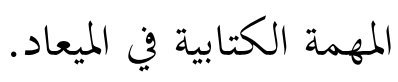

\section{منهجية البحث

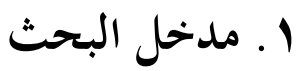

وقد استخدم الباحث في هذا البحث المدخل الكيفي، لأن إجراء

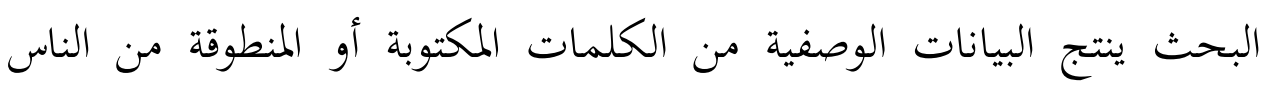

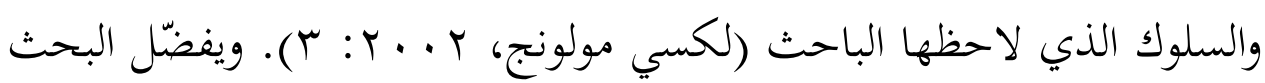

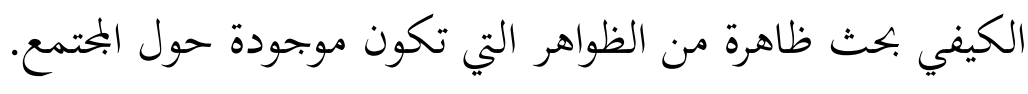

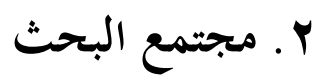

وأما بحتمع البحث في هذه الدراسة فهو المعلمون الذين يشرفون في مادة

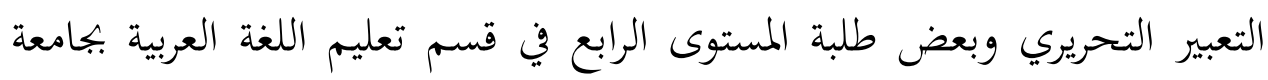

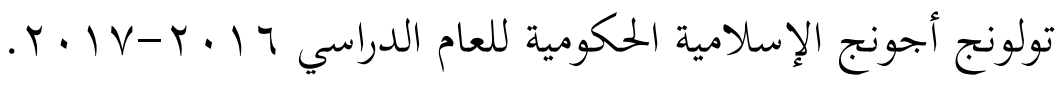

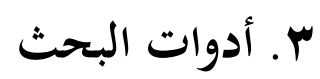

حتى يكصل الباحث على البيانات المطلوبة، استخدام الباحث عند جمع الباحت

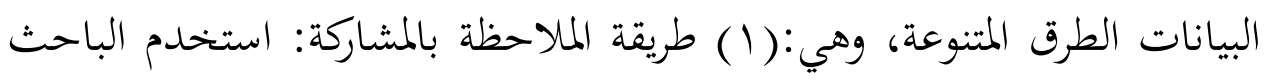


هذه الاستراتيجيات لطلب البيانات المتعلقة بمادة التعبير التحريري وكيفية عملية تقديمها المعلم واستعمالها أثناء عملية التعلم، والتعليم، وكيفية تصحيح أخطاء كتابة التعبير التحريري الطلبة في الفصل. وبهذه الطريقة، تستخدم الباحث لطلب البيانات المتعلقة باستراتيجيات التعلم التعاوني وأثرها في تعلم وتعليم التعبير التحريري وسلوك المعلم والطلبة فيها والمادة التعليمية للتعبير التحريري واستخدامها في تعلم وتعليم زيادة وتوكيدا مما حصل عليه الباحث من الملاحظة ونهيه بالمشاركة. (Y) المقابلة المتعمقة: قام الباحث بالمقابلة مع رئيس القسم والمعلمون لمادة التعبير التحريري وبعض الطلبة لمعرفة عملية تعليم مهارة التعبير التحريري

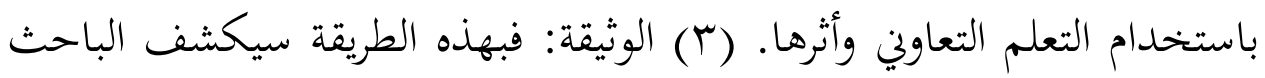
الحقائق أو البيانات على المواد المخططة، وأهداف تعليم التعبير التحريري، والمناهج، والخطة الدراسية، وأحوال الطلبة، وقسم تعليم اللغة العربية، وأوراق التعبير التحريري، وتصحيحها المعلم، وتعاليقة. ع. ع. أسلوب تحليل البحث

ويعمل الباحث تحليل البيانات في استخدام استراتيجيات بنشاطة تحليل البيانات في البحث الكيفي تعمل بتفاعلي واستمرار حتى إنتهاء النشاطة. وكان تحليل البيانات تستعمله الباحث على ثلاثة المراحل : وهي تنقيص البيانات (Data Reduksi)، وهو تخفين الحقايق الكثيرة في ميدان البحث ثم إختيارها

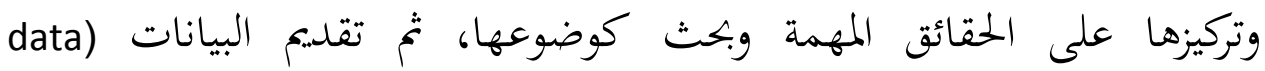
Display/penyajian (Conclution Drawing/Verification) وتتصف الخلاصة الأولى المعاضدة بالحقائق الصحيحة والمساوق فتحصل الخلاصة المصداقية. وبعد ذلك حاصل التحليل المشكل بالشرح يستخلص 
بشكل القصة. تحليل المتعددة الموقعة من تحليل البيانات هذا البحث يتكون على

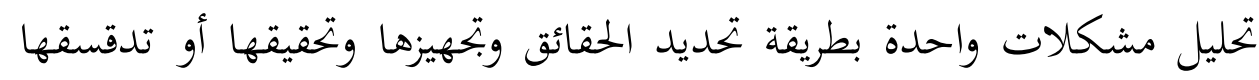

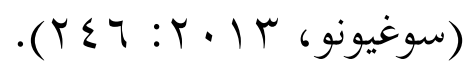

ثم إبرز النتائج والتأكيد صحة البيانات عن استراتيجيات التعلم التعاوني

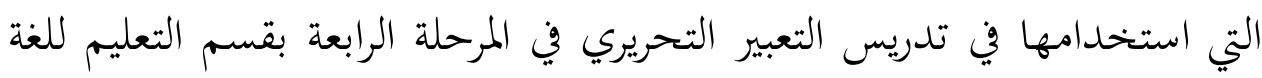

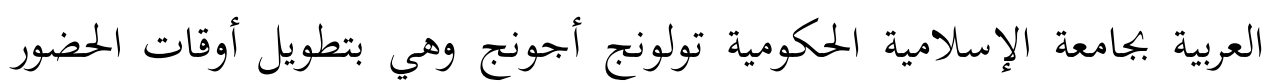
والمناقشة مع بعض الإخوان والتنتيش التثليثي (Trianggulasi).

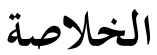

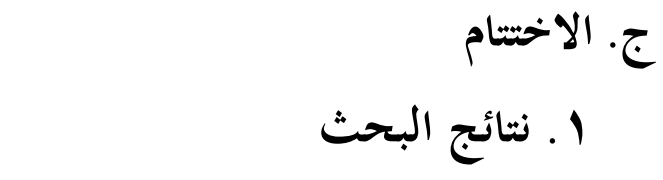

لقد توصل الباحث إلى النتائج، أهمها:

أ. ولتحقيق أهداف التعليم التعبير التحريري في قسم التعليم للغة العربية بالجامعِّ

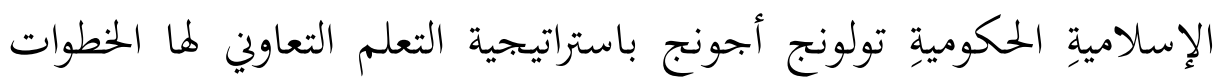
والإجراءات هي كما تلي: تعيين الموضوع، المادة والمرحلة والزمن، تعيين أهداف الدرس (الكفايات المطلوبة)، تعيين إجراءات التعليم (تقسيم المعلم

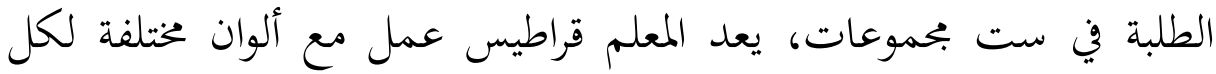

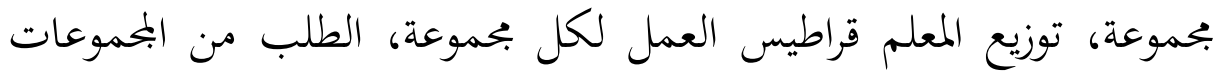

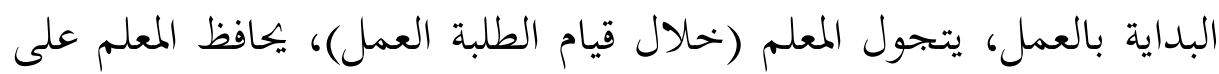
جو نشيط إيجابي مشوق للعمل، بعد انتهاء الطلبة من العمل، قامت كل

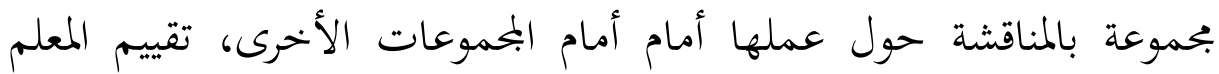

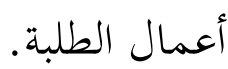


ب. استخدام استراتيجيات التعلم التعاوني لها أثر كبير عند الطلبة في ترقية المهارة

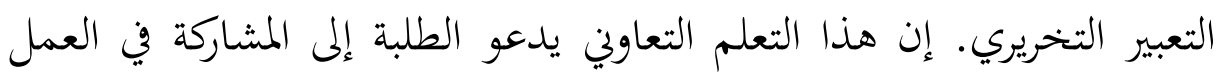

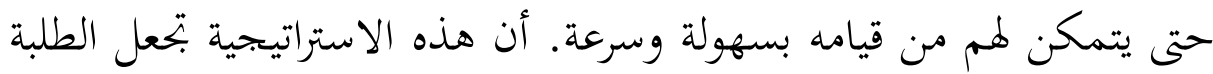

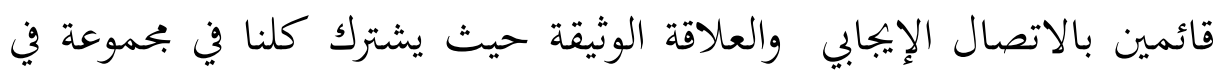

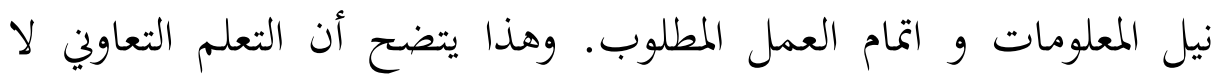

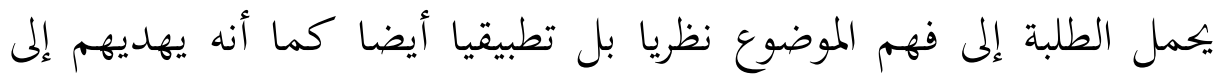

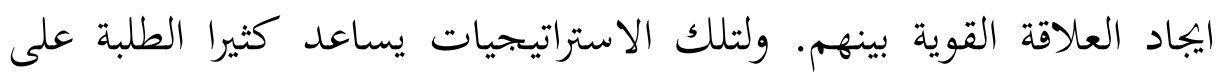
القيام بحل المشكلات يدا بيد حتى يمكن لهم أداء المهمة الصعبة بكل سرور

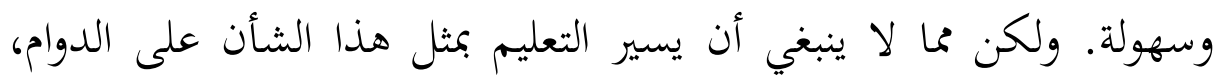
لأنه يقضي أوقاتا طويلة حتى لا يستطيع بعض الطلبة اتمام المهمة الكتابية في اني الميعاد.

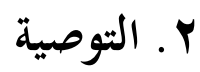

وبعد هذا المُتام، يرجى من هذا البحث أن يكون الاقتراحات عبرة

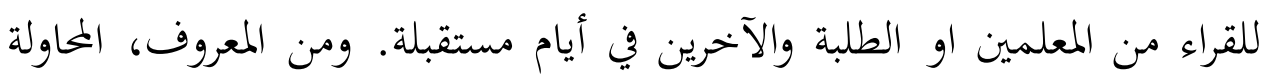

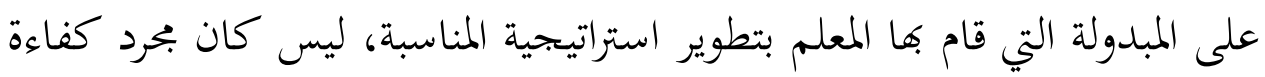

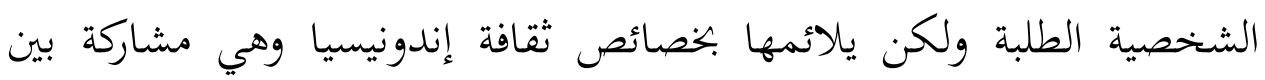

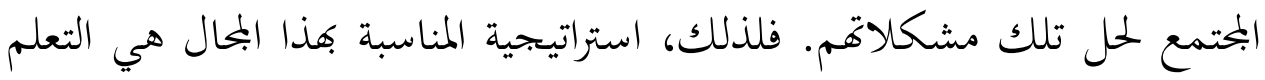
التعاوني الذي يعرض العمليات اللغوبية منها في تدريس مهارة التعبير التحريري بخصوصه أنه يفضل وظائف اللغة في استخدامها المتعلق بموقف التعاوني. وهذا

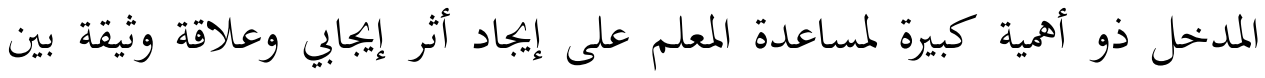

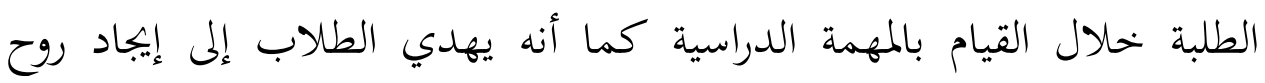
المشاركة والمعاونة بين أصدقائهم في فهم الدرس و اتمام العمل. واللة الموافق. 


\section{قائمة المراجع}

بحر الدين، أوريل. مهارة التدريس نحو إعداد مدرس اللغة العربية الكفء.ملانج: UIN r.11 6Press

الركابي، جودت. طرق تدريس اللغة العربية، دمشق: دار الفكر. 1990

عبيدات، ذوقان وسهيلة ابو السميد، استراتيجيات التدريس في القرن الحادي و

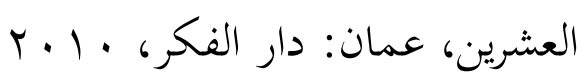

عارفة، زكية. تعليم الإنشاء المشكلات والحلول مالانج: مطبعة جامعة مولانا ملك

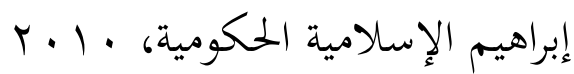

غاز المفلح، دليل تدريس اللغة العربية في مناهج التعليم العام، طا، الرياض: مكتبة

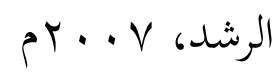

مدكور، علي أحمد. تدريس فنون اللغة العربية. القاهرة: دار الفكر العربي، و منشور، محمد وكستيون. دليل الكاتبتى المترجم. جكرتا: مويو سغورو اغغ، ب . ب النجار، بسام، برنامج مقترح لتنمية بعض مهارات التعبير الكتابي الإبداعي لدى طلبة الصف العاشر بمحافظة غزة، رسالة دكتوراه غير منشورة، غزة: جامعة عين

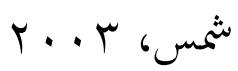

Abu Bakar, Muhammad. Metode Khusus Pengajaran Bahasa Arab. Surabaya: Usaha Nasional, 1981

Afifuddin Dimyathi, Muhammad. Panduan Praktid Menulis bahasa Arab Sidoarjo: Lisan Arabi, 2016

Bahruddin, Uril, Rekonstruksi Pengembangan Pendidikan Bahasa Arab. Sidoarjo: Lisan Arabi, 2017 
Bogdan dan Taylor dalam Lexy J Moleong, Metode Penelitian Kualitatif, Bandung : PT. Ramaja Rosda Karya, 2002

Isjoni, Cooperative Learning, Bandung: Alfabeta, 2009

Sugiono, Metodologi Penelitian Kuantitatif, kualitatif, dan $R \& D$. Bandung, Alfabeta, 2013

Trianto. Model-model Pembelajaran Inovatif berorientasi Konstruktivistik, Konsep, Landasan Teoritis-Praktis dan Implementasinya, Jakarta: Prestasi Pustaka, 2003

Effendi, Ahmad Fuad. Metodologi Pengajaran Bahasa Arab, Malang, Misykat, 2005

Zainuddin, Radliyah. Dkk. Metodologi dan Strategi Alternatif Pembelajaran Bahasa Arab. Yogyakarta: Pustaka Rihlah Group, 2005. 